\title{
Hacimsel Dane Oranının ve Dane Boyutunun Hamurda Kayaların (BIMRock) Dayanımı Üzerindeki Etkisi
}

\author{
The Effect of Volumetric Block Proportion and Grain Size on BIMRock Strength
}

\author{
Murat KARAHAN ${ }^{1}$, Hakan ERSOY ${ }^{1}$, M. Oğuz SÜNNETÇİ ${ }^{1}$, Özge ÖRGEN ${ }^{1}$ \\ ${ }^{1}$ Karadeniz Teknik Üniversitesi, Jeoloji Mühendisliği Bölümü, TRABZON
}

$\begin{array}{lll}\text { Geliş (received) } & : & 19 \text { Nisan (April) } 2016 \\ \text { Düzeltme (revised) } & : & 08 \text { Ağustos (August) } 2016 \\ \text { Kabul (accepted) } & : & 11 \text { Kasım (November) } 2016\end{array}$

Öz

Sağlam kaya bloklarının zayıf bir matriks tarafından kuşatıldığı heterojen kaya kütleleri hamurda kaya “BIMRock”olarak nitelendirilirler. Bu tür kaya kütlelerinde, laboratuvar çalışmalarında kullanılmak üzere standartlara uygun örnek almak ve hazırlamak çoğu kez zordur. Bu nedenle, bu tip kayalarda kayma direnci parametrelerinin ve tek eksenli sıkışma dayanımı gibi özelliklerin belirlenmesi oldukça güç olmaktadır. Literatürde, BIMRock'lar üzerinde, laboratuvar çalışmalarını ve ampirik yöntemleri konu alan çalışmalar oldukça azdır ve mevcut ampirik yöntemlerin sınırlamaları nedeniyle kaya mekaniği alanında bu konuda yaygın olarak kabul gören ampirik bir yaklaşım da mevcut değildir. Bu çalışma kapsamında ise farklı tane boyutlarında ve farklı hacimsel tane oranlarına sahip yapay BIMRock örnekleri hazırlanmış ve hazırlanan örnekler üzerinde tek eksenli sıkışma dayanımı direnci deneyleri yapılmıştır. Yapılan deneyler sonucunda tane boyutunun ve hacimsel tane oranının, yapay BIMRock örneklerinin tek eksenli sıkışma dayanımı üzerindeki etkisi araştırılmıştır. Test amacıyla 0.6 mm'den 9.5 mm'ye kadar değişen çapta çakı1 daneleri kullanılarak \% 20, \% 30 ve \% 40 arasında hacimsel dane oranına sahip yapay örnekler oluşturulmuştur. Matriks hazırlanırken su ve alçı kullanılmıştır. Dane boyutunun azalması durumunda tek eksenli sıkışma dayanımı değerleri 0.68 MPa' dan 0.45 MPa'a düşmüştür. Hacimsel dane oranının artması durumunda ise bu değerlerin 0.51 MPa'dan 0.66 MPa'a yükseldiği görülmüştür. Bu durum, dane boyutunda ve hacimsel dane oranındaki artmanın numunenin dayanımını artırdığını göstermektedir.

Anahtar Kelimeler: BIMRock, Dane Boyutu, Hacimsel Dane Oranı, Tek Eksenli Sıkışma Dayanımı.

M. Karahan

E-posta:muratkarahan@ktu.edu.tr 
Karahan, Ersoy, Sünnetçi, Örgen

\section{ABSTRACT}

Heterogeneous rock mass consisting of rock blocks that is surrounded by a weak matrix is regarded as block-in-matrix-rocks (Bimrock). Obtaining samples from this type of rock mass according to the standards and preparing them to be used in laboratory studies are often difficult. For this reason, it is quite difficult to determine the shear strength parameters and the mechanical properties such as uniaxial compressive strength in these sorts of rocks. There are just a few laboratory studies over bimrocks, and there isn't a widely accepted empirical approach in the field of rock mechanics available due to the limitations of the existing empirical methods. In scope of this work, synthetic Bimrocks samples were prepared with different grain sizes and different volumetric grain ratio. Uniaxial compressive strength tests were conducted on prepared samples. As a result of the experiments, the effect of grain size and volumetric grain proportion on the strength of artificial Bimrock samples were investigated. Artificial Bimrock samples with 20\%, 30\% and $40 \%$ volumetric grain proportions were prepared in the laboratory using gravel shaving diameters 0.6 to $9.5 \mathrm{~mm}$. Plaster and water were used to form matrix. The uniaxial compressive strengths of the test samples decrease from $0.68 \mathrm{MPa}$ to $0.45 \mathrm{MPa}$ as the grain size decreases; and increase from $0.51 \mathrm{MPa}$ to $0.66 \mathrm{MPa}$ as the volumetric grain proportion increase. The results indicate that the uniaxial compressive strength of Bimrocks increases with increasing grain size and volumetric grain proportion.

Keywords: Bimrock, Volumetric Grain Proportion, Grain size, Uniaxial Compressive Strength.

\section{GIRIŞ}

Barajlar, göletler, tüneller, şevler ve temeller gibi mühendislik yapılarının projelendirilmeden önce, üzerine inşa edileceği ortamın jeolojik ve jeoteknik özelliklerinin ayrıntılı bir şekilde ortaya konması gereklidir. Jeolojik ortamın mühendislik özelliklerinin belirlenmesi sayesinde inşaat sirasinda ve sonrasinda meydana gelebilecek problemler önceden tespit edilebilir ve bu problemlerin çözümüne yönelik gerekli önlemler alınarak gerektiğinde uygun iyileştirmeler yapılabilir.

Herhangi bir mühendislik yapısının üzerine inşa edileceği ortam, her zaman kaya ya da zemin ortamı olmayabilir. Çoğu zaman mühendislik yapılarının tasarımı ve inşası melanj, ince tabakalı kaya ortamları, zayıf piroklastik kaya, aglomera, çok eklemi kaya ve fay breşleri gibi karmaşık yapıdaki jeolojik ortamlar üzerinde gerçekleştirilebilir. $\mathrm{Bu}$ tür ortamlar genellikle düzensiz, karışık, mekanik ve/veya boyutsal olarak heterojendir. Sağlam kaya bloklarının zayıf bir matriks tarafindan kuşatıldığ kaya ortamları da buna örnektir (Medley, 1994). $\mathrm{Bu}$ yapıdaki jeolojik ortamlarda, standartlara uygun örnek almak oldukça zordur. Dayanım ve deformasyon parametrelerinin belirlenmesi için önerilen laboratuvar deneyleri için gerekli yüksek kalitede karot numunelerin hazırlanamadığı durumlarda plaka yükleme, presiyometre, yassi veren ve dilatometre gibi bazı yerinde deneylerin uygulanması söz konusudur. Ancak bu deneylerin uygulanması için zaman alan ön hazırlıkların gerekmesi, sadece önem derecesi yüksek mühendislik yapılarında tercih edilmelerini de beraberinde 
getirmektedir (Altınsoy, 2006; Coşkun, 2010). BIMRock türü kaya kütlelerinin özelliklerinin ortaya konulması için, daha çok yapay örnekler üzerinde yapılan laboratuvar çalışmaları ve ampirik yaklaşımlar kullanılmaktadır. Jeolojik bir ortamın dayanım davranışı, Lindquist ve Goodman (1994) tarafindan hacimsel dane oranına göre isimlendirmişlerdir. Hacimsel dane oran $1 \% 25$ 'ten az ise matriks kontrollü, \% 25-\% 75 aralığındaysa tektonik "BIMRock" ve $\% 75$ 'ten büyük ise eklemli kaya kütlesi olarak isimlendirilmiştir. Ayrıca (Reidmüller vd., 2001; Altınsoy, 2006) "'BIMRock"ları "kaynaşmış" ve "kaynaşmamış" olarak iki sınıfta tanımlamış ve her iki sınıf için dayanım parametrelerinin belirlenmesine yönelik ampirik ilişkilerde MohrCoulomb ve Hoek Brown yenilme ölçütlerini önermişlerdir. Medley (1994) 'BIMRock"ları ölçekten bağımsız jeolojik malzemeler olarak tanımlamıştır. Bu durumda, matriks ile blok sınır boyutunun ayrımı, mühendislik uygulamasından etkilenen alan, hacim veya uzunluk ile ilişkilidir. Medley (1994) "A" etkileşim alanı olmak üzere, $0.05 *(\mathrm{~A})^{0.5}$ ten küçük bileşenin matriks, daha büyüklerinin ise blok olarak değerlendirilmesi gerektiğini önermiştir.

BIMRock'ların karakterizasyonu ve dayanım-deformasyon davranışlarını konu alan birçok çalışma mevcuttur (Bedrosian, 1978, 1980; Lindquist, 1994; Lindquist ve Goodman, 1994; Medley, 1994; Medley ve Lindquist, 1995; Gökçeoğlu, 2002; Medley, 2001; Reidmüller, 2001; Medley ve Rehermann, 2003; Sönmez vd., 2004, 2006; Altınsoy, 2006; Kahraman vd., 2008; Coşkun, 2010). Bu çalışmalarda, arazi verileri ve laboratuvarda hazırlanan yapay örnekler üzerinde yapılan çeşitli deneyler sonucunda elde edilen verilerden faydalanılarak bir takım ampirik yaklaşımlar da geliştirilmiştir. Çalışma kapsamında, farklı hacim oranlarında ve farklı boyutlarda agregalar kullanılarak yapay BIMRock örnekleri hazırlanmıştır. Farkl1 oranlarda ve boyutlarda danelerin kullanılmasının amacı ise hacimsel dane oranının ve dane boyutunun yapay örneklerin dayanımı üzerindeki etkisinin araştırılmasıdır.

\section{MATERYAL VE METOT}

Yapay "BIMRock" örneklerinin hazırlanmasında matriks olarak alçı-su karışımı, dane olarak da farklı dane boyutlarında riyolitik tüf agregaları kullanılmıştır. Altınsoy (2006), söz konusu çalışmasında, bentonit, alçı, çimento ve su karışımından oluşan bir matriks kullanmıştır. Coşkun (2010), A grubu yapay örneklerde kil ve su karışımından oluşan matriks, B grubu yapay örneklerde ise alç1, bentonit ve sudan oluşan matriks kullanmıştır. $\mathrm{Bu}$ çalışmada, kuruma süresinin azaltılması için bentonit, dayanımın düşük olması için çimento yerine, sadece su ve alçı karışımından oluşan bir matriks oluşturulmuştur. Farklı dane boyutlarındaki ve hacimsel yüzdelerdeki daneler, matriks ile homojen bir şekilde karıştırılarak 49.5 mm çapında silindirik PVC kalıplara dökülmüş ve boşluk kalmaması için yaş haldeyken şişlenmişlerdir. Dökülen örnekler 30-35 gün boyunca PVC kalıplarda kurumaya bırakılmış, açık havada kurumaya bırakılan örnekler bu süre zarfında düzenli olarak tartılmış ve son tartıya ait ağırlıklar eşit olunca örneklerin kuruduğu kabul edilmiştir. Kuruyan örnekler kalıplardan çıkarılarak deneye tabi tutulmuştur. Şekil 1'de farklı dane boyutlarındaki agregaların oluşturulma aşamaları, Tablo 1'de ise yapay BIMRock örneklerinin hazırlanmasında kullanılan agregaların hacimsel yüzdeleri ve dane boyutları verilmiştir. 
Karahan, Ersoy, Sünnetçi, Örgen

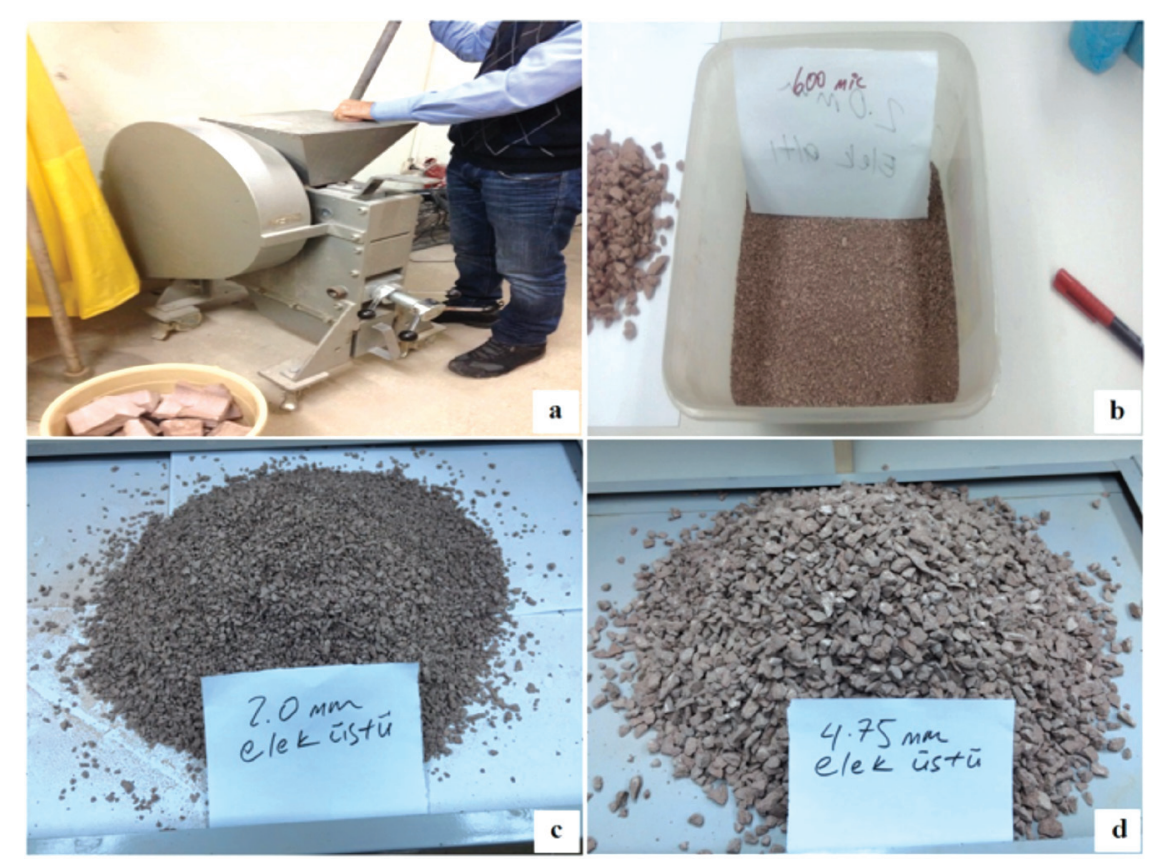

Şekil 1. (a) Riyolitik tüfün çeneli kırıcıda kırılması, (b) 0.6-2.00 mm boyutundaki agrega, (c) 2.00-4.75 mm boyutundaki agrega, (d) 4.75-9.50 mm boyutundaki agrega.

Figure 1. (a) Breaking of rhyolitic tuff in jaw crusher, (b) 0.6-2.0 mm diameter aggregates, (c) 2.0-4.75 mm diameter aggregates, (d) 4.75-9.5 mm diameter aggregates.

Çizelge1. Örneklerin hazırlanmasında kullanılan agregaların hacimce yüzdesi ve dane boyutları.

Table 1. Volumetric percentages and grainsizes of the aggregates used to prepare the samples.

\begin{tabular}{lcc}
\hline Dane Boyutu (mm) & $\begin{array}{c}\text { Hacimsel } \\
\text { Dane Oranı }\end{array}$ & $\begin{array}{c}\text { Örnek } \\
\text { Sayısı }\end{array}$ \\
\hline \multirow{2}{*}{ A Grubu (4.75-9.5) } & A-1 (\%20) & 5 \\
& A-2 (\%30) & 5 \\
& A-3 (\%40) & 5 \\
B Grubu (2.00-4.75) & B-1 (\%20) & 5 \\
& B-2 (\%30) & 5 \\
C Grubu (0.60-2.00) & B-3 (\%40) & 5 \\
& C-1 (\%20) & 5 \\
& C-2 (\%30) & 5 \\
D Grubu (0.60-9.5) & D-1 (\% 20) & 5 \\
& D-1 (\% 30) & 5 \\
Matriks & D-1 (\% 40) & 5 \\
\hline
\end{tabular}

Hazırlanan yapay "BIMRock” örneklerinin kaynaşmamış BIMRock sınıfinda olması için dane-matriks dayanım oranının en az 2 olması gerektiği Lindquist ve Goodman (1994) ve Medley (1994) tarafindan belirtilmiştir. Örneklerin hazırlanması için kullanılacak malzeme miktarını hesaplamak için matrikse ve danelere ait hacimsel oranlarda malzeme değerlerinin belirlenmesi gerekmektedir. Birim hacim ağırlıklar, istenilen bir yüzde hacimdeki malzeme kütlesinin hesaplanması için, tek eksenli sıkışma dayanımı değerleri ise dayanım oranının hesaplanması için kullanılmıştır. Dane ve matrikse ait doğal birim hacim ağırlıklarının ve tek eksenli sıkışma dayanımlarının hesaplanması için 11 adet riyolitik tüf örneğinden ve 5 adet matriksten elde edilen silindirik (çap $4.95 \mathrm{~cm}$ boy $12.5 \mathrm{~cm}$ ) örnekler kullanılmıştır (Tablo 2). 
Çizelge2. Silindirik örneklere $(\mathrm{D}=4.95 \mathrm{~cm}, \mathrm{H}=12.5 \mathrm{~cm})$ ait birim hacim ağırlık ve tek eksenli sıkışma dayanımı (UCS) değerleri. Table 2. Unit weight and uniaxial compressive strength (UCS) values of the cylindirical samples $(D=4.95 \mathrm{~cm}, H=12.5 \mathrm{~cm})$.

\begin{tabular}{|c|c|c|c|c|c|}
\hline & Açıklama & $\begin{array}{l}\text { Örnek Sayısı } \\
\quad \text { (Adet) }\end{array}$ & $\begin{array}{l}\text { Ortalama KBH } \\
\qquad\left(\mathrm{kN} / \mathrm{m}^{3}\right)\end{array}$ & $\begin{array}{c}\text { Ortalama Tek Eksenli Sıkışma } \\
\text { Dayanımı, UCS (MPa) }\end{array}$ & SD \\
\hline Rock & Riyolotik Tüf & 11 & 22.06 & 86 & 10.8 \\
\hline Matriks & $\% 60$ alçı+\% $40 \mathrm{su}$ & 5 & 16.5 & 0.55 & 0.1 \\
\hline
\end{tabular}

*KBH=Kuru Birim Hacim Ağırlık, **SD=Standart Sapma

Karot örneklerinin birim hacim ağırlık ve tek eksenli sıkışma dayanımı değerleri belirlendikten sonra yapay BIMRock örneklerinin hazırlanmas1 amaciyla farklı boyutlarda dane içeren numunelerin hazırlanması için, tüf örnekleri çeneli kırıcıda kırılmış, kırılan örnekler eleklerde elenerek dane boyu 0.6-2.00 mm, 2.00-4.75 mm ve 4.75-9.5 mm arasında değişen üç farklı gruba ayrilmıştır (Tablo 3). D grubu örnekler farklı dane boyutundaki malzemelerin eşit ağırlık oranlarında karıştırılması ile oluşturulmuştur.

Yapay matriks, kütlece \% 40 oranında su ve $\% 60$ oranında alçının homojen bir şekilde karıştırılması ile oluşturulmuştur. Kalıp olarak boyları $12.5 \mathrm{~cm}$, çapları ise $4.95 \mathrm{~cm}$ PVC kalıpları kullanılmıștır (Şekil 2a). Gerekli olan malzemeler hazırlandıktan sonra en son aşamada farklı boyutlarda ve farklı hacimsel yüzdelerde agrega kullanılarak yapay BIMRock örnekleri hazırlanmıştır. Örnekler hazırlanırken bilinen hacimsel oranlardan ve birim hacim ağırlıklardan faydalanılarak agrega ve matriksin ağırlıkları hesaplanmış, kütlece belli olan malzemeler tartılıp gerekli miktarlarda alınarak homojen bir şekilde karıştırılıp kalıplara dökülmüştür (Şekil 2b, c ve d). Hacimsel dane oranları \% 0 (matriks), \% 20, \% 30 ve \% 40 olan yapay örnekler hazırlanmış ve her hacimsel dane oranı içinde 3 farklı boyutta ve karışı boyutlarda agregalar kullanılmıştır.

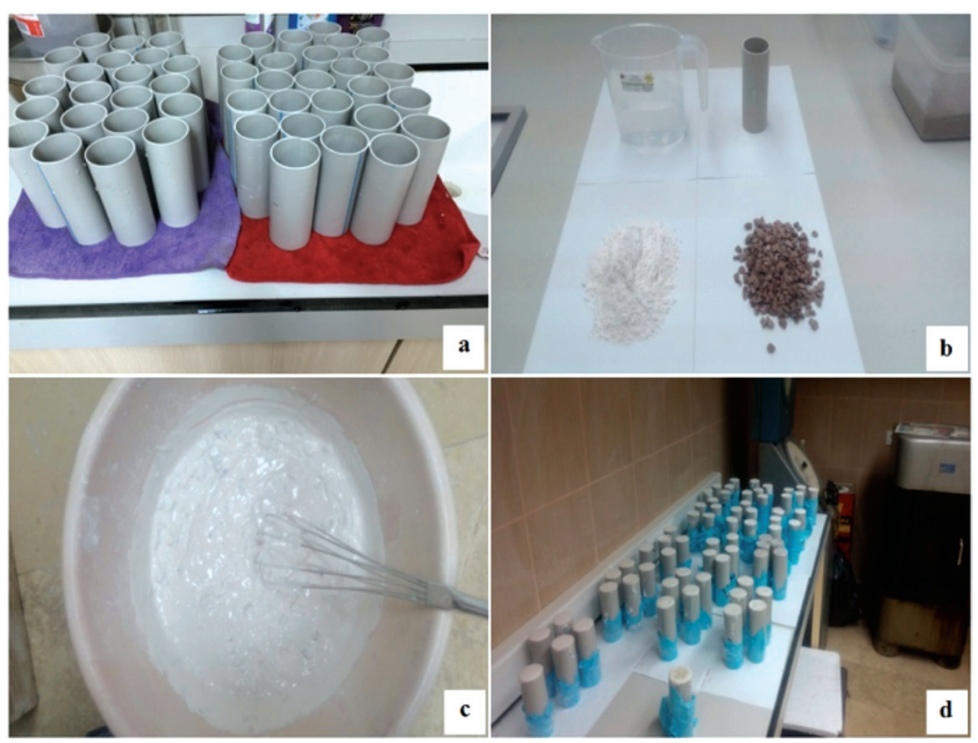

Şekil 2. (a) PVC borular, (b) kullanılan malzemeler, (c) hazırlanan karışım, (d) dökülen örnekler.

Figure 2. (a) PVC pipes, (b) used materials, (c) prepared mixture (d) prepared samples. 
Karahan, Ersoy, Sünnetçi, Örgen

Çizelge 3. Yapay BIMRock örneklerine ait ortalama serbest basınç direnci değerleri.

Table 3. The average unconfined compres sivestrength values of the artificial bimrock samples.

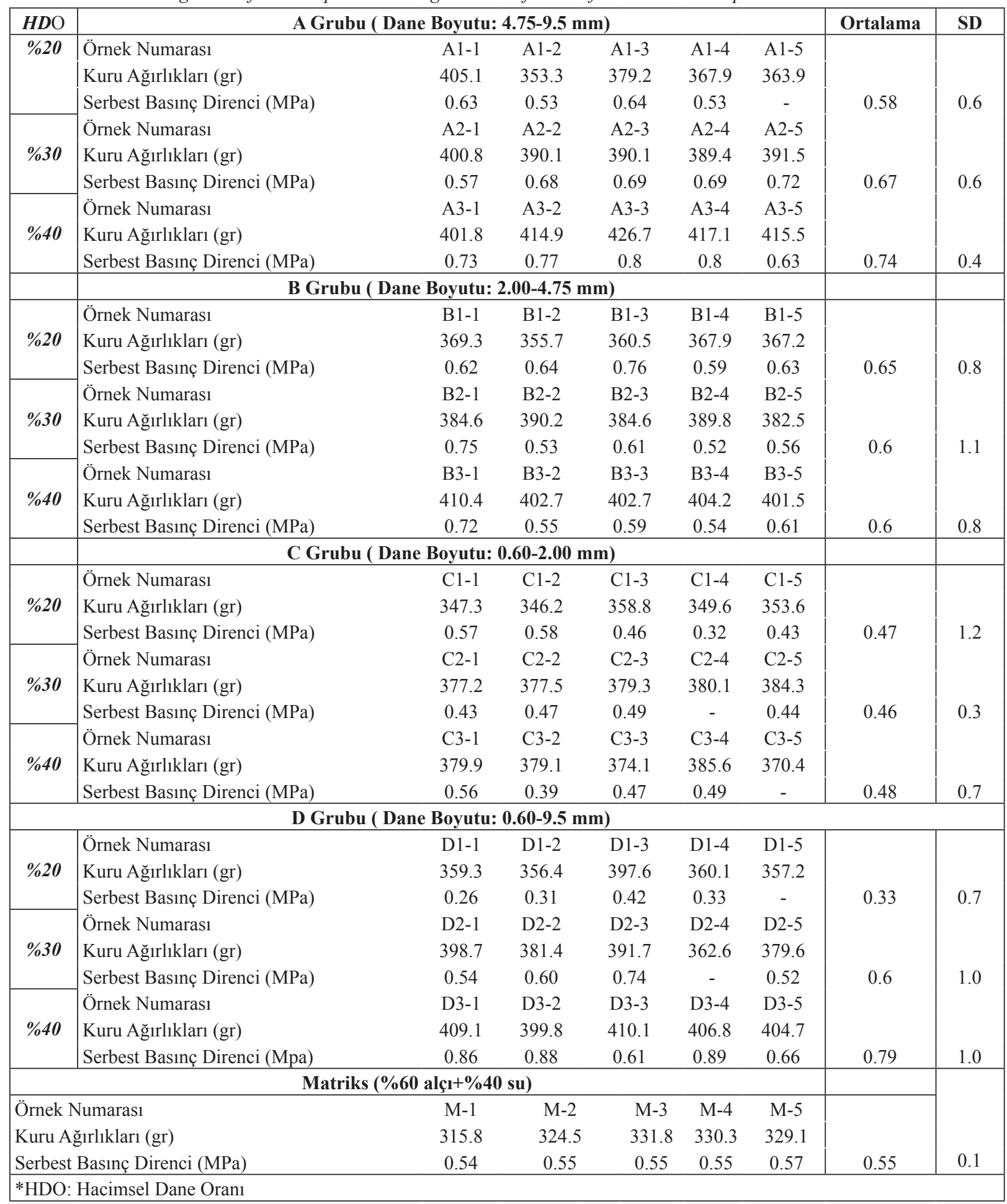




\section{BULGULAR}

Dane boyutu ve hacimsel dane oranının dayanım üzerindeki etkisinin araştırılması amaciyla 65 adet yapay BIMRock örneği tek eksenli sıkışma dayanımı deneyine tabi tutulmuştur. Yapılan deneyler sonucunda farklı dane boyutuna ve hacimsel dane oranına sahip her bir grubun ortalama tek eksenli sıkışma dayanımı hesaplanmıştır (Tablo 3). Her bir grup için 5 deney, toplamda ise 65 deney yapılmıştır.

Yapay örneklerin hazırlanmasında kullanılan agrega ve matriksin dayanım oranı 156 olarak bulunmuştur. $\mathrm{Bu}$ durumda hazırlanan yapay örnekler kaynaşmamış BIMRock sınıfina girmektedir (Reidmüller vd., 2001; Altınsoy, 2006). Yapılan deneysel çalışmalar sonucunda elde edilen bulgular sayesinde, ilk olarak, ayn örnekler üzerinde hacimsel dane oranı ile tek eksenli sıkışma dayanımı değerleri arasındaki ilişki belirlenmeye çalışılmıştır (Şekil 3). Şekil 3 incelendiğinde tüm dane boyutları için hacimsel dane oranının artmasının örneklerin tek eksenli sıkışma dayanımını artırdığı anlaşılmaktadır. Bu durum hacimsel dane oranının artması sonucunda matriksten kayaya geçiş olduğunun kanıtıdır.

$\mathrm{Bu}$ çalışmada, maksimum \% 40 oranında hacimsel dane oranına sahip örnekler hazırlanmıştır. $\mathrm{Bu}$ durumda kohezyonda çok az bir azalmanın ve danelerin artışına bağlı olarak içsel sürtünme açısında dikkate değer artışların meydana geldiği düşünülmektedir (önceki çalışmalarda yapılan deney sonuçları incelendiğinde). $\mathrm{Bu}$ durumda, blok oranının artışı tek eksenli sıkışma dayanımında, çok az da olsa bir artış meydana getirmiştir. Bu oran \% 10'u geçmemektedir.
Dane boyutuna bağlı olmaksızın her grup örnek için hacimsel dane oranının artışıyla birlikte tek eksenli sıkışma dayanımı (UCS) direnci değerlerinde artışın meydana geldiği görülmüştür. Özellikle D grubu örneklerde hacimsel dane oranı \% 20'den \% 30'a çıkarıldı̆̆ zaman UCS değerlerinde \% 85 oranında artış meydana gelmiştir. Yapay BIMRock ve matriks örneklerinin ortalama tek eksenli sıkışma dayanımı değerleri kıyaslandığında A, B ve D grubu örneklerin UCS değerlerinin matriksin değerinden yüksek, C grubu örneklerin ise düşük olduğu tespit edilmiştir. C grubu yapay örneklerin hazırlanmasında dane boyutu olarak 0.60-2.00 $\mathrm{mm}$ arasında değişen agregalar kullanılmıştır. Etkileşim alanı dikkate alındığında bu dane aralığında kullanılan agreganın matrikse dahil edilmesi gerektiği anlaşılmaktadır.

Çalışmanın ikinci aşamasında ise aynı hacimsel dane oranına fakat farklı dane boyutlarına sahip örneklerin tek eksenli sıkışma dayanımları ile dane boyutu ilişkisi araştırılmıştır (Şekil 3). Şekil 3 incelendiğinde, sabit hacimsel dane oranlarında dane boyutunun artmasının, örneklerin tek eksenli sıkışma dayanımını artırdığı anlaşılmaktadır. Karışık dane boyutuna sahip örneklerin (D grubu örnekler) daha yüksek tek eksenli sıkışma dayanımı değerlerine sahip olduğu belirlenmiştir. Ancak bu durum sadece \% 20 hacimsel dane örnek oranına sahip örneklerde bozulmuş, karışım örnekleri, en düşük tek eksenli sıkışma dayanımı değerleri vermiştir. Bunun nedeni, \% 20'lik dane oranında yeterli homojen karışımın sağlanamadığı şeklinde açıklanabilir. Aynı hacimsel dane oranında, dane boyutu arttıkça örneklerin tek eksenli sıkışma dayanımınlarında meydana gelen artışın nedeninin, dane boyutu arttıkça numunelerin içsel sürtünme açısının artması olduğu düşünülmektedir. 
Karahan, Ersoy, Sünnetçi, Örgen

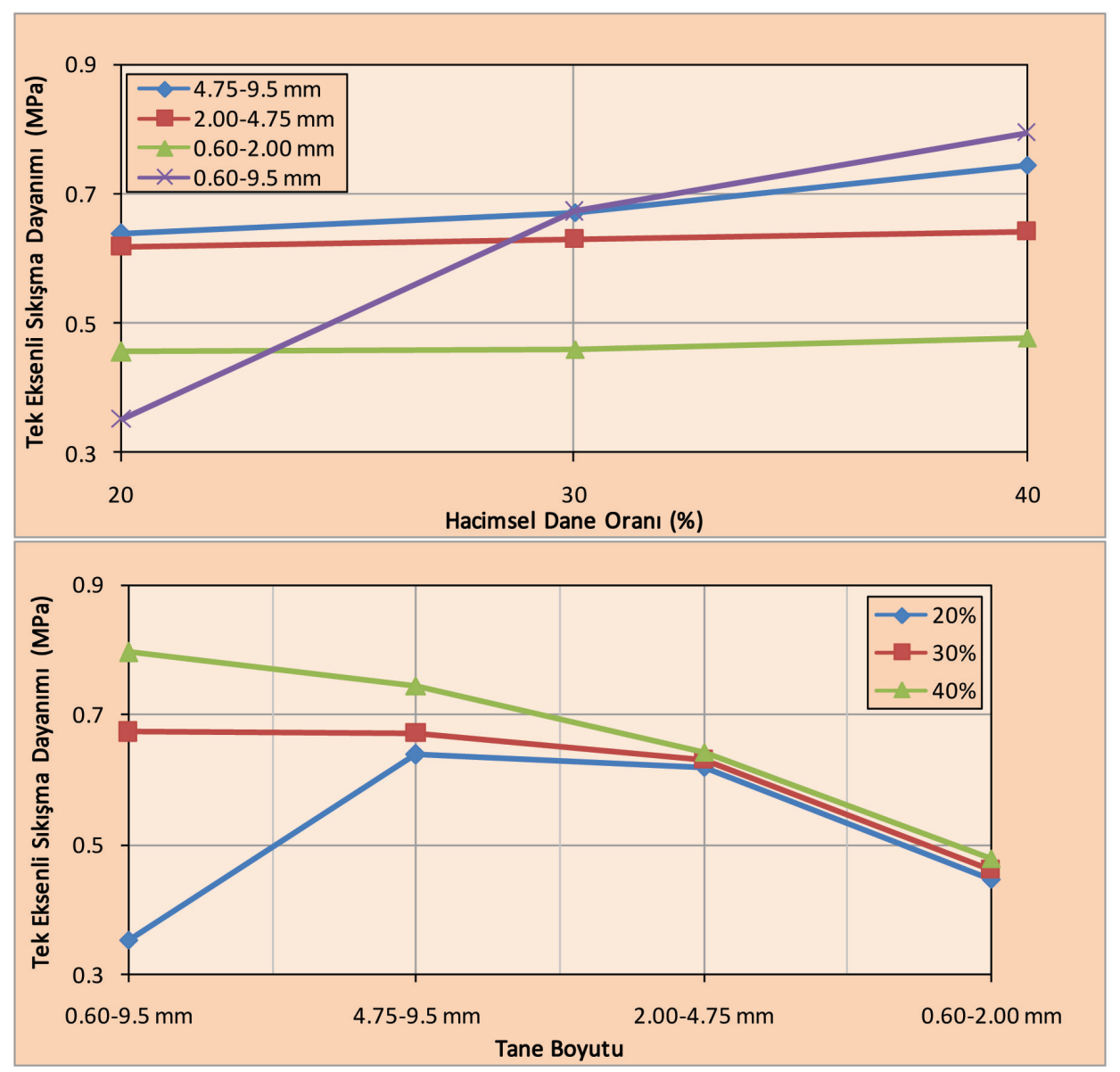

Şekil 3. Hacimsel dane oranının ve dane boyutunun örneklerin tek eksenli sıkışma dayanımı üzerindeki etkisi.

Figure 3. The effect of volumetric grain proportion and grain size on the uniaxial compressive strength.of the samples

\section{SONUÇLAR VE ÖNERÍLER}

$\mathrm{Bu}$ çalışma kapsamında, yapay olarak oluşturulan BIMRock örneklerinin dane boyutunun ve hacimsel dane oranının, tek eksenli sıkışma dayanımı üzerindeki etkisi araştırılmış, elde edilen sonuçlar aşağıda maddeler halinde sıralanmıştır:

1. Heterojen kaya örneklerinin BIMRock olabilmesi için, dane ve matriks dayanım oranının 2'den büyük olması durumu gözetilmiş, matriks oluşturulurken su ve alçı karışımından, granüler dane malzeme hazırlanırken riyolitik tüflerden yararlanılmıştır. Yapılan çalışma kapsamında dane-matriks dayanım oranı 156 olarak hesaplanmıştır.

2. 0.6 mm'den 9.5 mm'ye kadar değişen dane boyutunda, \% 20, \%3 0 ve \% 40 arasinda hacimsel dane oranına sahip yapay örnekler oluşturulmuş ve oluşturulan örneklerin tek eksenli sıkışma dayanımları tespit edilmiştir. Deneyler sonucunda hacimsel dane oranı artıkça tek eksenli sıkışma dayanımının arttığı görülmüştür. Hacimsel daneoranı $\% 20, \% 30$ ve $\% 40$ olan örneklerin tek 
eksenli sıkışma dayanımları sırası ile 0.330.65 MPa, 0.46-0.67 MPa ve 0.48-0.79 MPa arasında bulunmuştur.

3. Dane boyutunun BIMRock örneklerinin dayanımı üzerindeki etkisine bakıldığı zaman aynı hacimsel dane oranında, dane boyutunun artması ile örneklerin tek eksenli sıkışma dayanımının arttığı tespit edilmiştir. Bu durumun, dane çapının artmasıyla birlikte içsel sürtünme açısında meydana gelen artıştan kaynaklandığ 1 düşünülmektedir. Dane boyutuna göre hesaplanan ortalama tek eksenli sıkışma dayanımı değerleri 4.75$9.5 \mathrm{~mm}$ için $0.68 \mathrm{MPa}, 2.00-4.75 \mathrm{~mm}$ için $0.63 \mathrm{MPa}$ ve $0.60-2.00 \mathrm{~mm}$ için $0.46 \mathrm{MPa}$ bulunmuştur.

4. Yapay örneklerin dayanımları matriksin dayanımı ile kıyaslandığında, A, B ve D grubu örneklerin dayanımının matriksin dayanımından yüksek, C grubu örneklerin ise düşük olduğu bulunmuştur. C grubu örneklerin dayanımının matriksin dayanımından düşük olmasının, örnekler hazırlanırken içerisinde kalan hava kabarcıklarından kaynaklandığı düşünülmektedir.

5. Dane boyutunun artış1, dayanımı artırmaktadır ve aynı hacimsel dane oranına sahip farklı boyutlarda dane kullanılarak hazırlanan heterojen malzeme ile oluşturulan yapay örneklerin dayanımı, aynı boyuttaki agrega kullanılarak hazırlanan homojen malzeme ile oluşturulan yapay örneklerin dayanımından yüksektir (Tablo 3). Bu durum sadece hacimsel dane oran $1 \% 20$ olan karışık malzemeden hazırlanan örnekler için anomali vermiştir.
Çalışma kapsamına elde edilen veriler, karşılaşılan zorluklar ve değerlendirmeler doğrultusuna sunulan öneriler aşağıda maddeler halinde sıralanmıştır:

1. Yapay BIMRock örnekleri hazırlanmas1, çalışmanın en önemli ve belirleyici aşamasıdır. $\mathrm{Bu}$ aşamada, dane ve matriks arasındaki dayanım oranı çok yüksek tutulmamalıdır. $\mathrm{Bu}$ çalışmada dayanım oranının 156 olması çalışma için sorun teşkil etmese de, genelde bu tür yüksek değerler BIMRock örneklerinin danelerde bağımsız davranış göstermesine, dolayısıyla dayanımı matriksin kontrol etmesine neden olacaktır. Dayanım oranının çok yüksek değerlerde çıkmaması için, matriksin dayanımının artırılması gereklidir. Literatürde belirtilen örnek hazırlama tekniklerinde belirtildiği gibi matriksin dayanımını artırmak için karışıma bir miktar çimento eklemek gerekebilir.

2. Çalışmanın ilk aşamalarında matriks oluşturulurken karışımda alçı, su ve bentonit kullanılmıştır. Fakat iki aylık süre zarfı içinde örneklerin iç kısımlarının halen nemli olduğu ve örneklerin tam anlamıyla kurumadığı tespit edilmiştir. $\mathrm{Bu}$ olumsuzluktan ötürü karışımda sadece alçı ve su kullanılmıştır. Dayanım oranın çimento miktarıyla ayarlanması önerilmektedir.

3. Çalışma kapsamında hazırlanan yapay örneklerin, 30-35 gün içinde kuruduğu görülmüştür. $\mathrm{Bu}$ süreyi kısaltmak için örnekler kalıpta birkaç gün kurutulduktan sonra çıkartılarak kurumaya bırakılmıştır. $\mathrm{Bu}$ şekilde kurumanın, 8-10 günde tamamlandığ1 görülmüştür. Bu da zamanın en uygun şekilde değerlendirilmesi açısından önem arz etmektedir. 
Karahan, Ersoy, Sünnetçi, Örgen

4. Sonraki çalışmalar için, daha büyük çaplı kalıpların kullanılması ve etkileşim alanından faydalanarak minimum dane boyutunun seçilmesi önerilmektedir.

\section{KAYNAKLAR}

Altınsoy, H., 2006. Matriks içinde blok içeren kayaların makaslama dayanımın belirlenmesi için fiziksel model esaslı bir araştırma. Hacettepe Üniversitesi Fen Bilimleri Enstitüsü, Ankara, Yüksek Lisans Tezi, 104 s (yayımlanmış).

Bedrossian, T. L., 1978. Geology and slope stability in the Geysers Geothermal: Resources area, California Geology, 31, 151-159.

Bedrossian, T. L., 1980. Geology and slope stability in selected parts of the Geysers Geothermal resources area, No.142 of special reports: Sacramento, California, California Division of Mines and Geology, 66 p.

Coşkun, A., 2010. BIMRock (Hamurda Kaya) ile eklemli kaya kütlelerinin sınır koşulundaki sorunlara yönelik ampirik bir yaklaşımın geliştirilmesi. Hacettepe Üniversitesi Fen Bilimleri Enstitüsü, Ankara, Yüksek Lisans Tezi, $75 \mathrm{~s}$ (yayımlanmış).

Gökçeoğlu, C., 2002. A fuzzy triangular chart to predict the uniaxial compressive strength of the Ankara agglomerates from their petrographic composition. Engineering Geology, 66, 39-51.

Kahraman, S., Alber, M., Fener, M., Gunaydın, O., 2008. Evaluating the geomechanical properties of Misis fault breccia (Turkey). International Journal of Rock Mechanics and Mining Science, 45, 1469-1479.

Lindquist, E. S., 1994. The strength and deformation properties of melange, Ph.D. Thesis, University of California, Berkeley, $288 \mathrm{p}$ (published).

Lindquist, E. S., Goodman, R. E., 1994. The strength and deformation properties of a physical model melange, Proc. 1st North American Rock
Mechanics Conference (NARMS), Austin, Texas, eds. Nelson, P.P. and Laubach, S.E., A.A. Balkema, Rotterdam, 843-850.

Medley, E. W., 1994. The engineering Characterization of melanges and similar block-in-matrix rocks ("BIMRock"s), Ph.D. Thesis, University of California, Berkeley, 338 p (published).

Medley, E. W., Lindquist, E. S., 1995. The engineering significance of the scale-independence of some Franciscan melanges in California, USA, Proc. 35th US Rock Mechanics Symp, eds. Deamen, J.K. ve Schultz, R.A., Rotterdam: A.A. Balkema, 907-914.

Medley, E. W., 2001. Orderly Characterization of Chaotic Franciscan Melanges, Felsbau. Journal of Engineering Geology, Geomechanics and Tunnelling, 19 (4) 20-33.

Medley, E.W., Rehermann, P.S., 2003. Increases in slope stability of rock/soil mixtures due to tortuosity of failure surface around rock and blocks. GSA Conference, Seattle WA, November 2, 2003.

Reidmüller, G., Brosch, F. J., Klima, K., Medley, E. W., 2001. Engineering Geological Characterization of Brittle Faults and Classification of Fault Rock. Felsbau, Journal for Engineering Geologly, Geomechanics and Tunnelling, 19 (4/2001), 1319.

Sönmez, H., Tuncay, E., Gökçeoğlu, C., 2004. Models to predict the uniaxial compressive strength and the modulus of elasticity for Ankara agglomerates. International Journal of Rock Mechanics and Mining Science, 41(5), 717-729.

Sönmez, H., Gökçeoğlu, C., Medley, E. W., Tuncay, E., Nefeslioğlu, H. A, 2006. Estimating the Uniaxial Compressive Strength of a Volcanic "BIMRock", International Journal of Rock Mechanics \& Mining Sciences, 43, 554-561. 